\title{
Erratum to: Intraparenchymal, primary central nervous system lymphoma of low-grade $B$ cell malignancy: a case report with review of the literature on therapeutic consideration
}

\author{
Ryosuke Tomio - Hikaru Sasaki - Shigemichi Hirose - Takayuki Shimizu \\ Yuya Koda $\cdot$ Makoto Ohno $\cdot$ Yoshitaka Narita $\cdot$ Shunsuke Shibao • \\ Kazunari Yoshida
}

Published online: 1 August 2014

(C) The Japan Society of Clinical Oncology 2014

\section{Erratum to: Int Canc Conf J}

DOI 10.1007/s13691-014-0173-7

Unfortunately, Figs. 5 and 6 were swapped in the original publication of the article. The figures should appear as below:

The online version of the original article can be found under doi:10.1007/s13691-014-0173-7.

R. Tomio · H. Sasaki $(\bowtie) \cdot$ S. Shibao $\cdot$ K. Yoshida Department of Neurosurgery, Keio University School of Medicine, 35 Shinanomachi, Shinjuku, Tokyo 160-8582, Japan

e-mail: hsasaki@a5.keio.jp

\section{S. Hirose}

Department of Pathology, School of Medicine, Keio University,

35 Shinanomachi, Shinjuku, Tokyo 160-8582, Japan

T. Shimizu $\cdot$ Y. Koda

Division of Hematology, Department of Internal Medicine,

School of Medicine, Keio University, 35 Shinanomachi,

Shinjuku, Tokyo 160-8582, Japan

M. Ohno - Y. Narita

Department of Neurosurgery and Neuro-Oncology, National

Cancer Center Hospital, 5-1-1 Tsukiji, Chuo-ku,

Tokyo 104-0045, Japan 


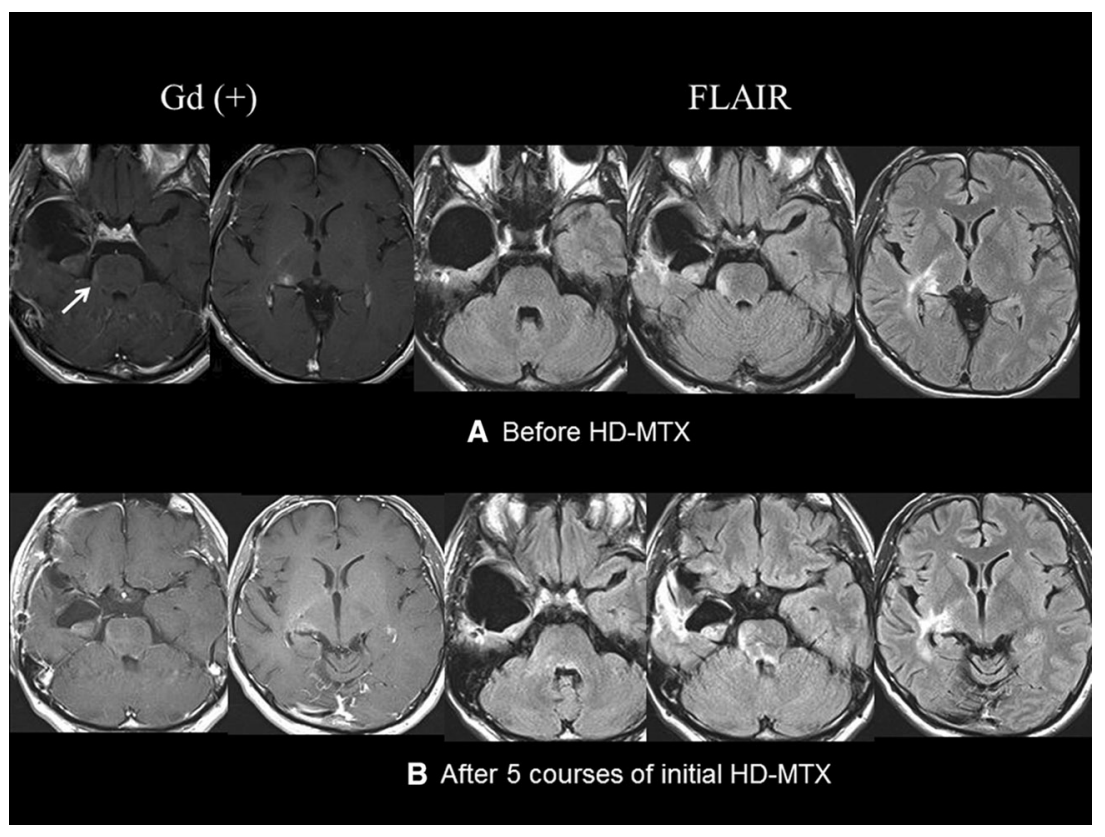

Fig. 5 Postoperatively, slight contrast-enhancement appeared on the right side of pons on MRI (arrow). Therefore, we started HD-MTX therapy $\left(3.5 \mathrm{~g} / \mathrm{m}^{2}\right)$ at 3 months after operation. The contrast-

enhancement on the right side of pons almost disappeared after 5 courses of HD-MTX

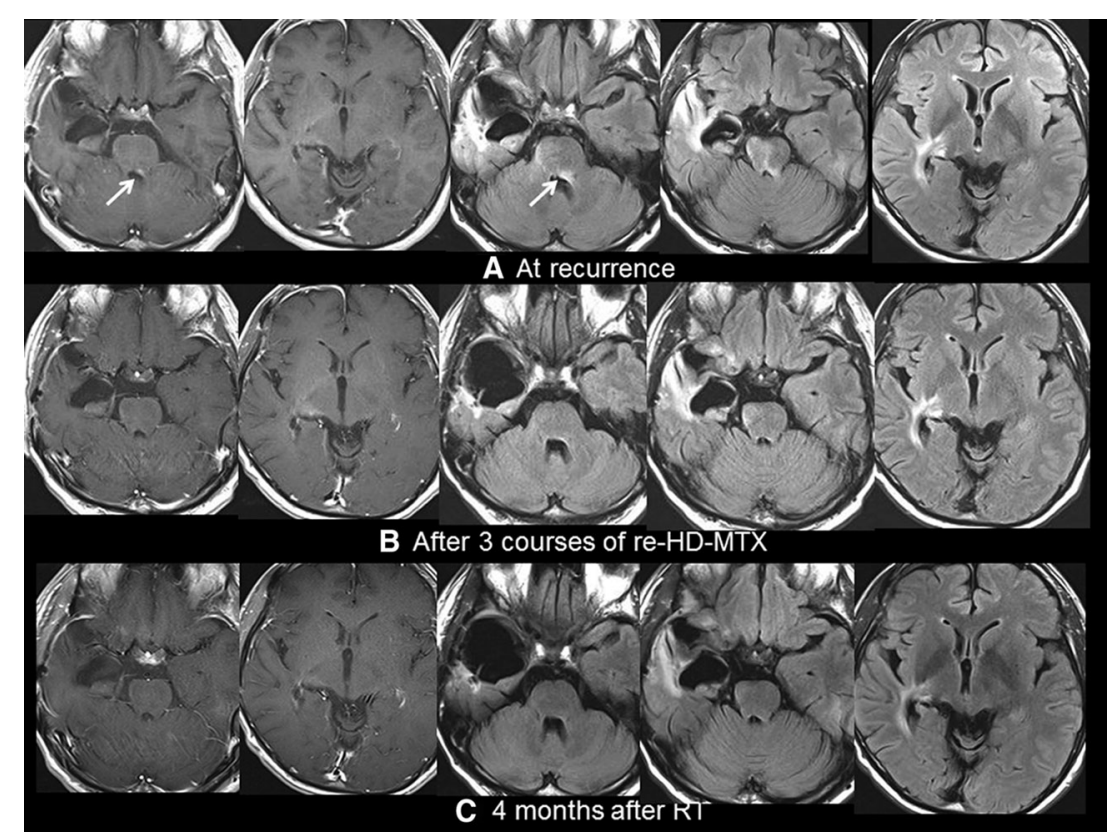

Fig. 6 MRI showed the new contrast-enhancement in the dorsal pons accompanied by expansion of high intensity area on FLAIR images only 1 month after completion of 5 courses of HD-MTX therapy (arrow). The patient was re-treated with 3 courses of HD-MTX $\left(4.5 \mathrm{~g} / \mathrm{m}^{2}\right)$ followed by whole brain irradiation (30 Gy). After irradiation, not only contrast-enhancement but also FLAIR-high intensity areas almost disappeared 